\title{
Epitaxial Growth of Graphene by Surface Segregation and Chemical Vapor Deposition on Ru(0001) Studied with Scanning Tunneling Microscopy
}

\author{
Won-Jun Jang and Se-Jong Kahng* \\ Department of Physics, Korea University, Seoul 136-713 \\ (Received September 13, 2013, Revised October 14, 2013, Accepted October 15, 2013)
}

\begin{abstract}
Epitaxial graphene on metal substrates provides excellent platforms to study its atomic and electronic structures, and can be grown either by surface segregation of carbon or by chemical vapor deposition. The growth behaviors of the two methods, however, have not been directly compared each other. Here, we studied domain structures of graphene grown by three different methods, surface segregation, post-annealing with adsorbed ethylene, and high-temperature dose of ethylene, using scanning tunneling microscopy. The first two methods resulted in graphene regions with areas of $100 \mathrm{~nm}^{2}$, whereas the third method showed large area graphene $\left(>10^{4} \mathrm{~nm}^{2}\right)$ with regular hexagonal Moiré patterns, implying that high-temperature dose of ethylene is preferable for further studies on graphene such as additional growth of organic molecules.
\end{abstract}

Keywords : Graphene, Ru(0001), STM, Epitaxial growth

\section{Introduction}

Graphene is a single layer of carbon atoms with honeycomb lattices [1]. Graphene has unique electronic structures such as Dirac cones with a linear energy-momentum relation due to its honeycomb lattice symmetries [1]. Due to its high carrier mobility $\left(2 \times 10^{5} \mathrm{~cm}^{2} \mathrm{~V}^{-1} \mathrm{~s}^{-1}\right)$, it has been expected that they can be used in future electronic devices [2]. Graphene can be obtained by exfoliating a layer from graphite bulk [1,3]. Although the exfoliation method is simple and cost-effective, it may not suitable to prepare large area graphene. Graphene can be also prepared by direct-growth methods such as surface segregation of carbon atoms and chemical vapor deposition on metal or semiconductor substrates [4-10]. In the former method, metal crystals that contain carbon impurities in its bulk are annealed to induce surface segregation of carbon atoms, then the carbon atoms floating on the surface form $\mathrm{sp}^{2}$ bonds each other making graphene layer $[4,6,10]$. In the latter method, hydrocarbon molecules are introduced to metal substrates on which carbon-hydrogen bonds are catalytically broken to make desorption of hydrogen molecules and adsorption of carbon atoms which as a result form graphene layer. In the former methods, no

* [E-mail] sjkahng@korea.ac.kr 
additional carbon source is required, whereas in the latter methods, it is easy to control the amount of carbon atoms for graphene growth [5-10]. Although these two methods are widely used to prepare graphene on metal substrates, there has been no direct comparison on the growth behaviors in the two methods available in literatures.

In this paper, we present growth structures of graphene prepared by three different methods, surface segregation, post-annealing with adsorbed ethylene, and high-temperature dose of ethylene, using scanning tunneling microscopy (STM). We observed that both surface segregation and post-annealing methods resulted in graphene islands with areas of $100 \mathrm{~nm}^{2}$ and that high-temperature dose method showed large area graphene with regular hexagonal Moiré patterns.

\section{Experiment}

Our experiments were performed with a home-built STM system that has a base pressure below $7 \times 10^{-11}$ torr. STM imaging was carried out at a sample temperature of $300 \mathrm{~K}$. A single crystal $\mathrm{Ru}(0001)$ was cleaned by repeated cycles of $\mathrm{Ne}$-ion sputtering, flashing in $\mathrm{O}_{2}$ pressure of $1 \times 10^{-7}$ torr at $1,600 \mathrm{~K}$, and flashing in vacuum. Ethylene for graphene growth and $\mathrm{H}_{2}$ gas (Sigma Aldrich, USA) for hydrogenation were dosed using a stainless steel tube (3 $\mathrm{mm}$ diameter) through a precision leak valve. STM images were obtained in constant current mode with a Pt/Rh tip.

\section{Results and Discussion}

Transition metals such as $\mathrm{Ru}, \mathrm{Ni}$, and Ir may contain significant amount of carbon impurities their bulk because of their high solubility at room temperature. At high temperature $(>1,000 \mathrm{~K})$, the car- bon atoms tend to float on the surface, because their bulk and surface diffusivities become large enough to achieve a transition from a dilute alloy to a segregated equilibrium phase of graphene [11]. This high temperature transition has been used to grow graphene on metal substrates. Fig. 1(a) shows a typical STM image obtained after this surface segregation procedure, by simply annealing $\mathrm{Ru}(0001)$ at $1,300 \mathrm{~K}$. We observed the regions with hexagonal Moiré patterns as show in in the inset of Fig. 1(a). Because there is $8.9 \%$ lattice mismatch between graphene and substrate $\mathrm{Ru}(0001)$, the Moiré patterns mean that the region is covered with graphene [4-10]. We measured
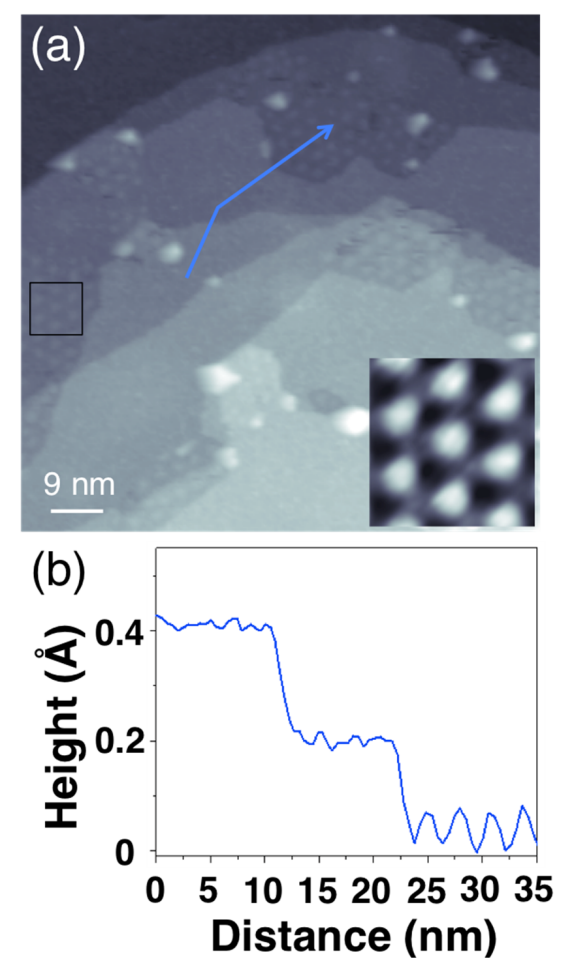

Figure 1. A typical (a) STM image and (b) a height profile of epitaxial graphene on $\mathrm{Ru}(0001)$ grown by surface segregation of carbon atoms. Inset of (a): a zoomed image of the region marked by a square in (a). Image size of (a): $90 \times 90 \mathrm{~nm}$, the sample bias: $\mathrm{V}_{\mathrm{s}}=-1.3 \mathrm{~V}$, and the tunneling current: $I=0.1 \mathrm{nA}$. Image size of the inset of (a): $8 \times 8 \mathrm{~nm}$, the sample bias: $V_{s}=1.0 \mathrm{~V}$, and the tunneling current: $\mathrm{I}=0.1 \mathrm{nA}$. The height profile is taken along the arrow in Fig. (a). 
step height of $\mathrm{Ru}(0001)$, period and the corrugation of the Moiré patterns as $2.1 \AA, 3 \mathrm{~nm}$ and $0.08 \AA$, respectively, as shown in Fig. 2(b). Although these values show good agreement with previous studies with graphene on $\mathrm{Ru}(0001)[4,8,9]$, the typical area of graphene regions was rather small $200 \mathrm{~nm}^{2}$, implying that our Ru substrate had only a fraction of carbon impurities in bulk. Because there is no way to in-
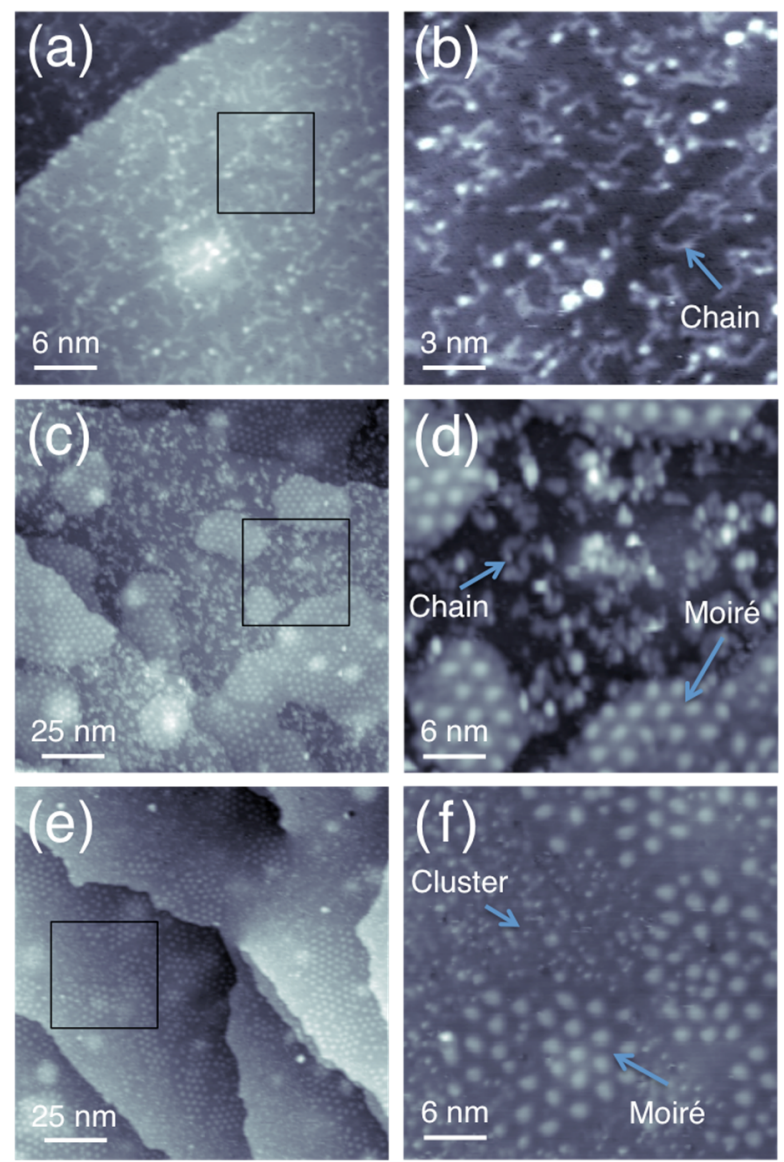

Figure 2. Typical STM images obtained after post-annealing procedures at (a), (b) $800 \mathrm{~K},(\mathrm{c}),(\mathrm{d})$ 1,100 K, (e), (f) 1,300 K. (a) Image size: $36 \times$ $36 \mathrm{~nm}$, the sample bias: $\mathrm{V}_{\mathrm{s}}=-1.8 \mathrm{~V}$, and the tunneling current: $I=0.1 \mathrm{nA}$. (b) Image size: $18 \times 18 \mathrm{~nm}$, the sample bias: $\mathrm{V}_{\mathrm{s}}=-1.8 \mathrm{~V}$, and the tunneling current: $I=0.1 \mathrm{nA}$. (c), (e) Image size: $150 \times 150 \mathrm{~nm}$, the sample bias: $V_{s}=-2.0$ $\mathrm{V}$, and the tunneling current: $l=0.1 \mathrm{nA}$. ( $\mathrm{f}$ ) Image size: $36 \times 36 \mathrm{~nm}$, the sample bias: $V_{s}=$ $-2.0 \mathrm{~V}$, and the tunneling current: $\mathrm{l}=0.1 \mathrm{nA}$. (b), (d) and (f) are the zoomed image of (a), (c) and (e), respectively. crease the amount of carbon in this method, in the next step, we tried chemical vapor deposition.

Ethylene gas was introduced to our ultra-high vacuum chamber as a source for carbon. We studied two different growth procedures, post-annealing with adsorbed ethylene, and high-temperature dose of ethylene. In the post-annealing procedures, 90 Langmuir ethylene was exposed to $\mathrm{Ru}(0001)$ at room temperature, and then ethylene-adsorbed $\mathrm{Ru}(0001)$ was annealed at one of the temperatures, 800, 1100, and 1,300 K. Fig. 2 shows typical STM images obtained after these post-annealing procedures. In the STM images after $800 \mathrm{~K}$ annealing, Moiré pattern was not observed, but irregular chain-like structures were found [See Fig. 2(a) and (b)]. A typical length of chains was $3 \mathrm{~nm}$, which is about 10 times larger than the length of one ethylene molecule [12]. The chain-like structures are hydrocarbons polymerized from ethylene molecules. Some parts of carbon-hydrogen bonds in ethylene molecules are broken at $800 \mathrm{~K}$ with the help of catalytic activity of $\mathrm{Ru}(0001)$, and subsequently form chain-like hydrocarbons. In the STM images after 1,100 $\mathrm{K}$ annealing, we observed both Moiré patterned graphene regions and chain-like structures [See Fig. 2(c) and (d)]. The length of chain-like structures was noticeably reduced. After 1,300 K annealing, we observed similar Moiré patterned graphene regions but cluster-like structures instead of chain-like structures [See Fig. 2(e) and (f)]. The cluster-like structures are another form of hydrocarbon or amorphous carbon which is quite stable at high-temperature. Even if annealing temperature was increased higher than $1,300 \mathrm{~K}$, no significant change from Fig. 2(e) and (f) was observed in Moiré patterned graphene regions and cluster-like structures. The area of graphene regions did not increase because of limited supply of carbon atoms similar to previous surface-segregation method.

Fig. 3 shows two STM images obtained from the same region, including a hexagon shaped graphene 
region, at different sample voltages, -1.3 and -0.1 $\mathrm{V}$. The two images showed different heights both at inner parts and edges of graphene region. The heights of graphene region obtained at $-0.1 \mathrm{~V}$ was smaller than those at $-1.3 \mathrm{~V}$, due to electronic effect at lower voltage [14]. At the edge, the height differ-
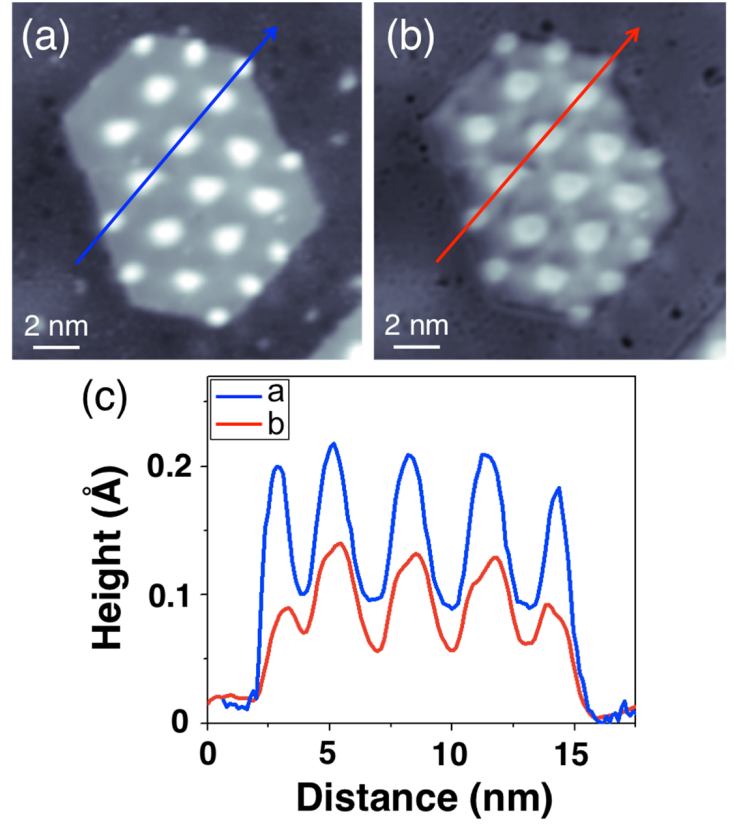

Figure 3. (a, b) STM images of a hexagonal shaped graphene island obtained at different sample voltages. (c) The height profile is taken along the arrows of (a) and (b). (a) Image size: $15 \times 15 \mathrm{~nm}$, the sample bias: $\mathrm{V}_{\mathrm{s}}=-1.3 \mathrm{~V}$, and the tunneling current: $l=0.1 \mathrm{nA}$. (b) Image size: $15 \times 15 \mathrm{~nm}$, the sample bias: $V_{s}=$ $-0.1 \mathrm{~V}$, and the tunneling current: $\mathrm{I}=0.1 \mathrm{nA}$. ence was enhanced, similar to substrate effects or edge states effects of nano-ribbons studied on $\mathrm{Au}(111)$ [15]. Although we were unable to find any confinement states, in general surface segregation and post-annealing methods can be used to prepare small graphene regions $\left(<100 \mathrm{~nm}^{2}\right)$ suitable to study confinement or edge effects [13].

When we grew graphene by high-temperature dose of ethylene, we were able to obtain large area graphene $\left(>10^{4} \mathrm{~nm}^{4}\right)$. Fig. 4(a) and b show typical STM images obtained after dosing ethylene gas while keeping the substrate at $800 \mathrm{~K}$, followed by annealing at 1,300 K. We observed that STM images were fully covered with Moiré patterned graphene without any chain or cluster-like structures. The Moiré patterns showed very regular hexagonal ordering with the same period and corrugation observed in Fig. 1. We further obtained atomic resolution STM images as shown in Fig. 4(c). Instead of honeycomb lattices, hexagonal lattices were observed, implying that the symmetry between two atoms in a unit cell was broken due to the interaction between carbon atoms in graphene and $\mathrm{Ru}$ atoms in substrate [6]. The lattice constant of hexagonal structure was measured to be $2.45 \AA$, in agreement with bulk value. As ethylene molecules arrive at high temperature $\mathrm{Ru}(0001)$, they may have preferred adsorption configurations on surface in which carbon-hydrogen bonds are immedi-
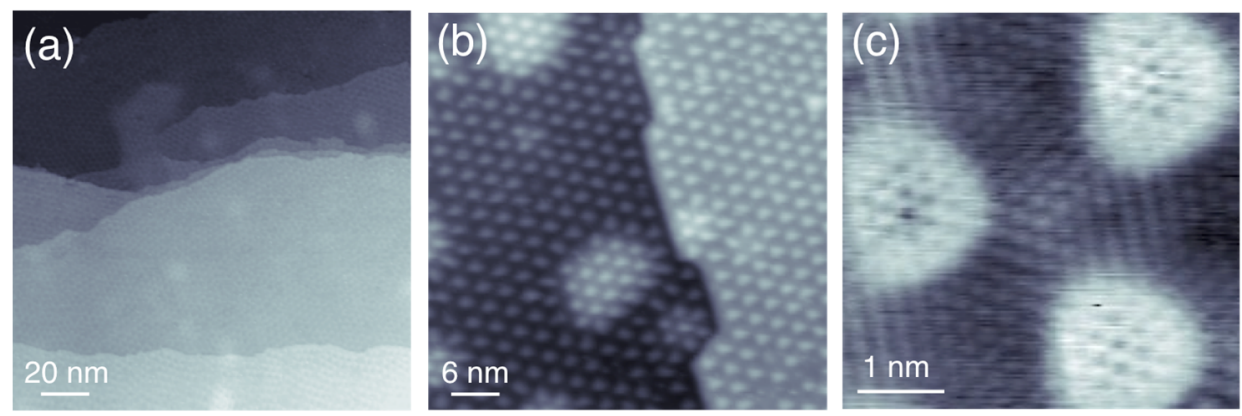

Figure 4. (a), (b), (c) STM images of epitaxial graphene on Ru(0001) grown by high temperature dose method. (a) Image size: $170 \times 170 \mathrm{~nm}$, the sample bias: $\mathrm{V}_{\mathrm{s}}=-0.8 \mathrm{~V}$, and the tunneling current: $\mathrm{I}=0.1 \mathrm{nA}$. (b) Image size: $50 \times 50 \mathrm{~nm}$, the sample bias: $\mathrm{V}_{\mathrm{s}}=-0.8 \mathrm{~V}$, and the tunneling current: $\mathrm{l}=0.1 \mathrm{nA}$. (c) An atomic resolution STM image. Image size: $4.5 \times 4.5 \mathrm{~nm}$, the sample bias: $V_{s}=0.2 \mathrm{~V}$, and the tunneling current: $I=0.1 \mathrm{nA}$. 
ately broken, activating desorption of hydrogen molecules, adsorption, and diffusion of carbon atoms on surface. Thus carbon atoms in ethylene molecules participate in graphene lattices shortly after ethylene molecules arrive on surface, not impeded by intermediate structures such as chain or cluster-like structures. The key in such growth processes is the increased catalytic activity of $\mathrm{Ru}$ substrate at high temperature, compared with that at room temperature.

\section{Summary}

We studied the structures of graphene grown by three different methods, surface segregation, postannealing with adsorbed ethylene, and high-temperature dose of ethylene, using STM. We observed that both surface segregation and post-annealing methods resulted in graphene islands with areas of $100 \mathrm{~nm}^{2}$ and that high-temperature dose method showed large area graphene with regular hexagonal Moiré patterns. Our study shows that high-temperature dose of ethylene is preferred for further studies on graphene such as additional growth of organic molecules.

\section{References}

[1] A. H. Castro Neto, N. M. R. Peres, K. S. Novoselov, and A. K. Geim, Rev. Mod. Phys. 81, 109 (2009).

[2] S. H. Ji, J. B. Hannon, R. M. Tromp, V. Perebeinos, J. Tersoff, and F. M. Ross, Nat. Mater. 11, 114
(2012).

[3] A. K. Geim and K. S. Novoselov, Nat. Mater. 6, 183 (2007).

[4] S. Marchini, S. Gunther, and J. Wintterlin, Phys. Rev. B 76, 075429 (2007).

[5] P. W. Sutter, J. I. Flege, and E. A. Sutter, Nat. Mater 7, 406 (2008).

[6] J. Wintterlin and M. L. Bocquet, Surf. Sci. 603, 1841 (2009).

[7] Y. Pan, H. Zhang, D. Shi, J. Sun, S. Du, F. Liu, and H. J. Gao, Adv. Mater. 21, 2777 (2009).

[8] B. Borca, S. Barja, M. Garnica, M. Minniti, A. Politano, J. M. Rodriguez-Garcia, J. J. Hinarejos, D. Farias, A. L. V. de Parga, and R. Miranda, New J. Phys. 12, 093018 (2010).

[9] D. Martoccia, M. Bjorck, C. M. Schleputz, T. Brugger, S. A. Pauli, B. D. Patterson, T. Greber, and P. R. Willmott, New J. Phys. 12, 043028 (2010).

[10] P. Sutter and E. Sutter, Adv. Mater. 23, 2617 (2013).

[11] J. C. Shelton, H. R. Patil, and J. M. Blakely, Surf. Sci. 43, 493 (1974).

[12] C. H. Chung, W. J. Jung, and I. W. Lyo, Phys. Rev. Lett. 97, 116102 (2006).

[13] F. Craes, S. Runte, J. Klinkhammer, M. Kralj, T. Michely, and C. Buss, Phys. Rev. Lett. 111, 056804 (2013).

[14] J. Tersoff and D. R. Hamann, Phys. Rev. Lett. 50, 1998 (1983).

[15] Y. C. Chen, D. G. de Oteyza, Z. Pedramrazi, C. Chen, F. R. Fischer, and M. F. Crommie, ACS Nano 7, 6123 (2013). 


\title{
주사형 탐침 현미경을 이용한 $\mathrm{Ru}(0001)$ 위 그래핀의 에피탁시얼 성장 조건에 대한 연구
}

\author{
장원준 · 강세종* \\ 고려대학교 물리학과, 서울 136-713
}

(2013년 9월 13일 받음, 2013년 10월 14일 수정, 2013년 10월 15일 확정)

\begin{abstract}
금속 기판 위에 성장한 그래핀은 원자구조와 전자구조 연구에 우수한 기반이 된다. 그래핀은 금소 기판에서 탄소의 surface segregation 이나 chemical vapor deposition으로 성장할 수 있는데, 이 두 방법의 성장 양상에 대한 비교 연구는 아직까지 없었다. 본 연구에서는 surface segregation, 흡착된 에틸렌의 post-annealing, 에틸렌의 high-temperature dose 등 3 방 법으로 성장한 그래핀의 성장구조를 주사형 터널링 현미경으로 연구했다. 처음 2 종류의 방법에서는 $100 \mathrm{~nm}^{2}$ 수준의 작은 그 래핀 영역이 나타났고, 3 번째 방법에서는 $10^{4} \mathrm{~nm}^{2}$ 보다 큰 그래핀이 육각형 무아레 무늬와 함께 타나났다. 본 연구에서는 에 틸렌의 high-temperature dose 방법이 추가적인 분자성장 등에 필요한 넓은 그래핀을 성장하기에 가장 좋은 방법임을 보였 다.
\end{abstract}

주제어 : Graphene, Ru(0001), STM, Epitaxial growth

* [전자우편] sjkahng@korea.ac.kr 